\title{
Efficacy of a Nutritional Supplement, Standardized in Fatty Acids and Phytosterols, on Hair Loss and Hair Health in both Women and Men
}

\author{
Federica Zanzottera ${ }^{1^{*}}$, Gioia Bizzaro ${ }^{2}$, Angela Michelotti ${ }^{2}$ and Vincenzo Nobile ${ }^{2}$ \\ ${ }^{1}$ Private Practice Trichology, Milano, Italy \\ ${ }^{2}$ Complife Group, Garbagnate Milanese, Italy
}

*Corresponding author: Federica Zanzottera, Private Practice Trichology, Milano, Italy, Tel: +393482441779; E-mail: federica.zanzottera@hotmail.it

Received date: April 27, 2017; Accepted date: June 07, 2017; Published date: June 14, 2017

Copyright: (C) 2017 Zanzottera F, et al. This is an open-access article distributed under the terms of the Creative Commons Attribution License, which permits unrestricted use, distribution, and reproduction in any medium, provided the original author and source are credited.

\section{Abstract}

Introduction: Hair health concern is one of the most distressing conditions for a significant number of men and women of all ages. The unique current pharmacologic therapeutic options approved by Food and Drug administration (FDA) are finasteride and topical minoxidil; however, these treatments may have side effects and may work on just one cause of hair loss, without giving an exhaustive and complete results.
\end{abstract}

Objective: The aim of this study was to evaluate the efficacy of a nutritional complex, combining omega 3-6-9, antioxidant, natural inhibitors of $5 \alpha$-reductase and anti-inflammatory molecules in improving hair loss and hair health parameter such as volume, strength and reduction of greasiness.

Methods: This study was made up of two phases. The in vitro experiment aimed at evaluating the capacity of the nutritional complex to lower the enzyme $5 a$-reductase activity in culture of human keratinocytes. The in vivo study was performed on 30 volunteers who experienced a 6 months treatment with the nutritional complex. The evaluation of hair loss and hair health parameter was performed by trichoscopy, global photograph review and subject's assessment.

Results: The in vitro study showed the capacity of the nutritional formulation to inhibit the total $5 a$-reductase comparable to finasteride and Serenoa repens. The global photograph assessment at $T_{0}$ and $T_{6}$ showed an increased hair density on $83.3 \%$ of subjects and the preliminary results were already visible just after three months. Moreover, the trichoscopy demonstrates an increase of hair diameter and hair density, an improvement of vascularization and a reduction of greasiness at the follicle level. The hair quality and hair loss reduction valued by the subjects showed positive results confirming the photographic outcomes.

Conclusions: This study proves the action of nutritional complex components, B-sitosterosl with omega 3-6 complex from Serenoa repens, linseed, borage, wheat oils, pine bark and rye grass in inhibition of the total $5 \alpha-$ reductase. Furthermore, both the reduction of hair greasiness and the improvement of hair quality demonstrate that this formulation is not only effective against 5 a-reductase but it also exerts its properties in a complete manner by restoring the physiologic condition of a healthy scalp. Moreover, it demonstrates the positive effects of this natural complex supplementation on overall scalp coverage. Visibly there is an improvement of vascularization, hair diameter and the reduction of hair loss perception.

Keywords: Androgenetic alopecia; Nutritional supplement; Hair loss; Hair growth; Female pattern hair loss; Omega 3 and 6; Antioxidants

\section{Introduction}

In the modern society, hair loss and hair health concern are one of the most distressing condition for a significant number of men and women of all ages.

Among the most common causes of hair loss, we can list: i) Androgenetic Alopecia (AGA), an inherited condition which is likely to appear in males [1], characterized by progressive thinning of scalp hair and defined by various patterns [2-3]. ii) Female pattern hair loss (FPHL), a diffuse reduction in hair density which affects the crown and the frontal scalp, frequently observed after puberty and affecting up to $50 \%$ of women over 50 [4-6]. iii) Telogen effluvium (TE), an intense hair shedding and diffuse thinning of hair on the scalp, usually incurring after pregnancy, stressing conditions, surgery or hormonal changes [1].

The androgen dihydrotestosterone (DHT) is thought to play a large role in inducing AGA and FPHL. DHT is formed from the conversion of circulating testosterone by $5 \alpha$-reductase ( $5 \alpha$ Red); once converted it binds the androgen receptor with five times the avidity of testosterone and is more potent in its ability to cause downstream activation, this results in hair thinning on androgen-sensitive hair follicles $[7,8]$.

There are three known isoenzymes of $5 a$ Red receptors, types II and I play an important role in the treatment of AGA [9]. Type I 5aRed is located predominantly in the skin, including sebaceous glands and hair follicles, whereas type II is the major contributor to the DHT pool and is located in the inner root sheath of hair follicles in the scalp, beard and chest as well as the genitals and prostate gland [10]. 
The unique current pharmacologic therapeutic options approved by Food and Drug Administration (FDA) aimed to treat AGA, FPHL and TE are finasteride and minoxidil [11].

Finasteride is a synthetic azo-steroid that is a potent and highly selective antagonist of $5 \alpha$ Red type II. It is not an anti-androgen but it binds irreversibly to the enzyme and inhibits the conversion of testosterone to dihydrotestosterone. Finasteride was initially FDA approved for use in benign prostate hyperplasia $(\mathrm{BPH})$, but seeing the hair growth as a side effect, it was adopted to treat AGA in 1997. The underlying principle for its use in AGA is the reduction of DHT production in order to limit its action on scalp hair follicles [12-14].

Minoxidil is a chemical compound ( $\mathrm{C} 9 \mathrm{H} 15 \mathrm{~N} 5 \mathrm{O})$ that has been used to treat hypertension since the 1960s [15]. Hypertrichosis as a consequence of minoxidil treatment was observed shortly thereafter and has been said to occur in $100 \%$ of the users $[15,16]$. These observations led to the development of topical minoxidil as a treatment for hair loss [17] and it was approved by the FDA for the treatment of male androgenetic alopecia in 1984. Minoxidil is a vasodilator that increases the cutaneous blood flow to the scalp [18] and also a potassium channel opener, which cause hyperpolarization of cell membranes, allowing more oxygen, blood and nutrients to reach the follicle [19]. Minoxidil contains an N-oxide group able to release NO, and besides being a vasodilator [20-23], it acts as a nitric oxide agonist. However, it has no therapeutic action on the hormonal and genetic causes of hair loss.

Although finasteride and minoxidil are excellent treatments, they may have side effects. Finasteride can cause fertility and libido reduction in men while hirsutism in women, furthermore, the females of childbearing age are forbidden to use finasteride due to its potential negative effects on fetus [24]. Minoxidil can cause skin redness and tachycardia [20]. Besides, these pharmacological products work only on one cause of hair loss, DHT reduction finasteride and microcirculation at follicle level minoxidil, without giving an exhaustive and complete result.

In the last ten years, it has been discovered that hair loss is not only due to hereditary factors, but also to inflammation, oxidation, hormones and vascular factors, which are involved and play a major role in the etiology of hair loss pathologies [21-24].

There are no doubts that nutrition influences hair loss and hair conditions $[25,26]$. Nowadays, the approach is developing natural/ herbal formulation, in order to take care of these conditions by avoiding harmful side effect.

The aim of this open labels non-comparative study was to evaluate the efficacy of the nutritional complex, combining omega 3-6-9, antioxidant, natural inhibitors of $5 \alpha$ Red and anti-inflammatory molecules, in improving hair loss and hair health parameters such as volume, strength and reduction of greasiness.

\section{Material and Methods}

\section{Dosage of enzyme 5aRed activity in culture of human keratinocytes (ATCC-PCS-200-010)}

The experimental protocol has provided the dosage of enzyme activity marker, the dihydrotestosterone (DHT) in:

Untreated cell culture (negative control, CTR-);
Cell cultures treated with finasteride (Finasteride $\geq 98 \%$ powder from Sigma Aldrich (F12939)) $1 \mu \mathrm{g} / \mathrm{ml}$, corresponding to $5 \mathrm{mg} /$ day human which is the highest dose used in AGA and FPHL pharmacological treatment [27].

Cell cultures treated with Serenoa repens (Saw Palmetto, Serenoa repens, fruit fat-soluble extract (oil), $\geq 85.0 \%$ total fatty acids from $\mathrm{NvH}$, Italy) $40 \mu \mathrm{g} / \mathrm{ml}$, corresponding to $200 \mathrm{mg} /$ day human dose, which is the most common dosage, used for hair reinforce food supplements [28].

Serenoa repens is a plant of the Arecaceae's family, also known as Saw palmetto, used in therapy for AGA. It acts as a competitive, nonselective inhibitor of $5 a$ Red types I and II [28].

Cell cultures treated with nutritional complex (Table 1) $30 \mu \mathrm{g} / \mathrm{ml}, 60$ $\mu \mathrm{g} / \mathrm{ml}$ and $100 \mu \mathrm{g} / \mathrm{ml}$ corresponding to $150 \mathrm{mg} /$ day, $300 \mathrm{mg} /$ day and $500 \mathrm{mg} /$ day human dose. This dose was established considering a medium human blood volume of $5 \mathrm{~L}$ and assuming a total absorption of the product.

\begin{tabular}{|l|l|l|l|}
\hline Components & Botanical name & Plant Part & Composition \% \\
\hline Borage OIL & Borago officinalis & Seed & $>25<50$ \\
\hline Linseed OIL & $\begin{array}{l}\text { Linum } \\
\text { usitatissimum }\end{array}$ & Seed & $>25<50$ \\
\hline Wheat GERM OIL & Triticum vulgare & Germ & $>25<50$ \\
\hline Saw palmetto OIL & Serenoa repens & Fruit & $>10<25$ \\
\hline $\begin{array}{l}\text { Phytosterols from } \\
\text { Pine EXTRACT }\end{array}$ & Pinus sylvestris & Bark & $>0.5<5$ \\
\hline Rye EXTRACT & Secale cereale & Flower & $>0.5<5$ \\
\hline
\end{tabular}

Table 1: Nutritional complex components (NaturSYN Beaulixir ${ }^{\mathrm{TM}}$ kindly provided by Amitalia S.r.l, Solaro, MI, Italy).

The cells were seeded in 96-well plates at $1 \times 10^{4}$ cells/well and maintained at standard culture condition $\left(37^{\circ} \mathrm{C}\right.$ in $\left.5 \% \mathrm{CO}_{2}\right)$.

At the end of the treatment periods respectively of 24 and $48 \mathrm{~h}$, culture media were collected and stored at $-80{ }^{\circ} \mathrm{C}$ until ELISA determinations were performed.

Culture media of controls and cells treated with tested product were used for the dosage of dihydrotestosterone according to ELISA method.

Commercial kits were used for the determination. ELISA uses the competitive bound between an antigen (in this case the DHT) and its primary antibody. The immune complex (antigen-antibody) was bond by a secondary antibody conjugated to a peroxidase. The addition of the enzyme substrate gives a colorimetric reaction with intensity proportional to the immune complex, providing the DHT quantity.

The quantitative determination uses a calibration curve made-up of standard known and growing concentrations of standard DHT.

\section{Statistical analysis}

An intention to treat statistical analysis was performed using NCSS 8 (version 8.0.4 for Windows; NCCS, LLC., Kaysville, UT, USA). Data were checked for normality using either the Shapiro-Wilk W, Kolmogorov-Smirnov, and D'Agostino omnibus normality tests. If the 
Citation: Zanzottera F, Nobile V, Bizzaro B, Michelotti A (2017) Efficacy of a Nutritional Supplement, Standardized in Fatty Acids and Phytosterols, on Hair Loss and Hair Health in both Women and Men. J Cosmo Trichol 3: 121. doi:10.4172/2471-9323.1000121

Page 3 of 7

data were normal, the repeated measure analysis of variance (RMANOVA) followed by Tukey-Kramer multiple comparison test was performed both intra- and inter- group comparisons. If data were not normal, the Wilcoxon signed-rank test was performed for intra-group comparisons, whereas the Mann-Whitney $U$ test was performed for inter-group comparisons. Values are expressed as arithmetic mean \pm standard deviation (SD). P value 0.05 was considered significant.

\section{Trial design and participants}

All the study procedures were carried out according to World Medical Association's (WMA) Helsinki Declaration and its amendments (Ethical Principles for Medical Research Involving Human Subjects, adopted by the 18th WMA General Assembly Helsinki, Finland, June 1964 and amendments).

In order to take part to the study each participant was fully informed on study risks and benefits, aims and procedures both.
Informed consent form and consent release form for the publication of photographs were signed by the subjects prior the attendance to the study.

This 6-months non-comparative, open label pilot study was conducted from January 2016 to October 2016 in Italy. The aim was to evaluate the efficacy of a nutritional supplement on hair loss and hair conditions.

Thirty patients composed of 15 males and 15 females, fulfilling the inclusion and exclusion criteria and showing at least one of the hair loss leading conditions laid down in (Table 2), were enrolled in the study. Each patient's medical history and treatment details were recorded; moreover, the clinical examination of both hair and scalp was carried out to evaluate pattern and grade of hair loss.

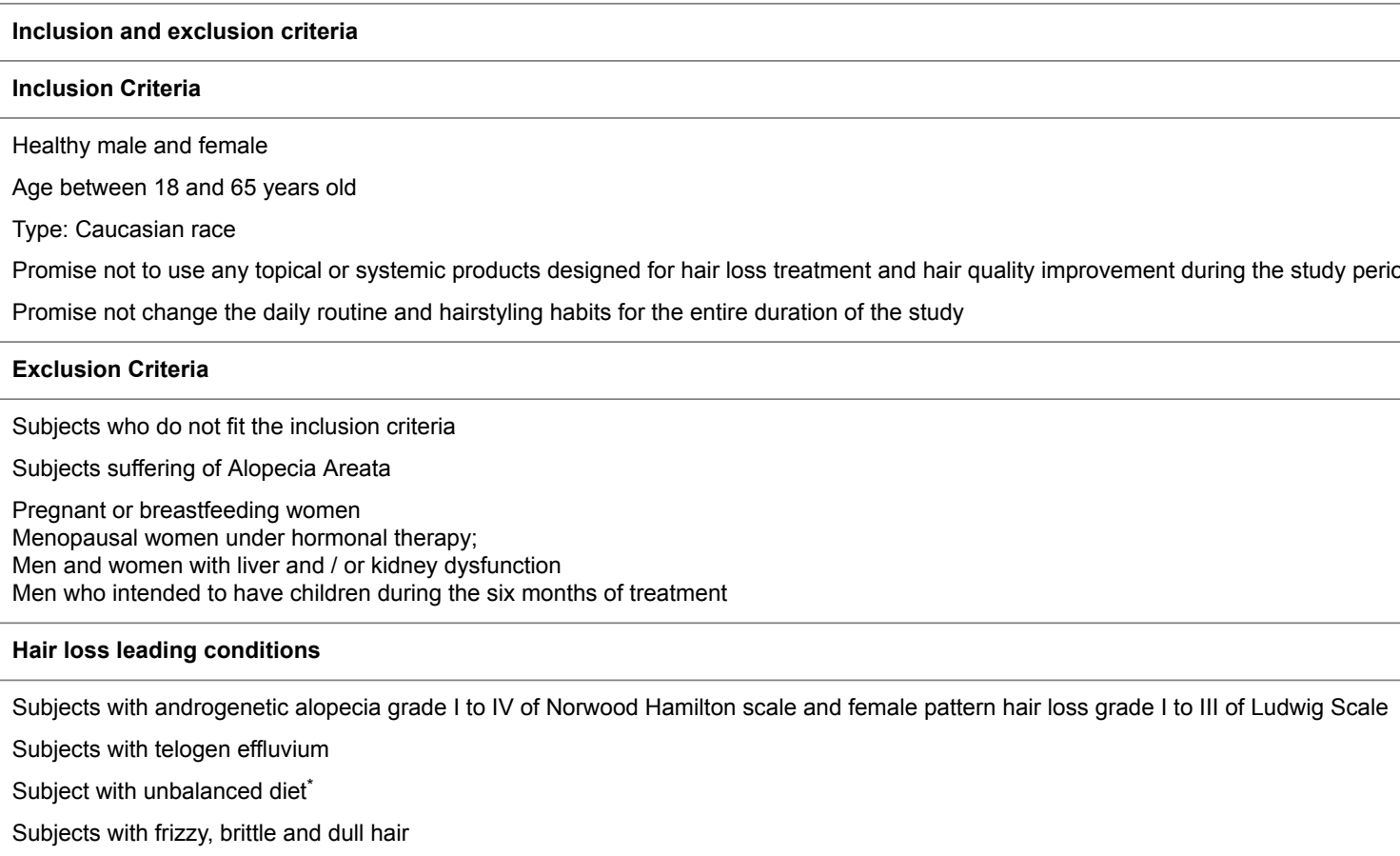

Table 2: Description of the inclusion and exclusion criteria for the volunteers' recruitment. Description of hair loss leading conditions (( ${ }^{*} T h e$ daily diet was evaluated by the analysis of a "Daily diet agenda" in which the volunteer had to indicate all the meals and drinks they had during one week before the first visit. The agenda was analysed by a nutritionist. Unbalance diet: proteins $<0.7 \mathrm{~g} / \mathrm{kg}$; carbohydrates $>65 \%$ En; PUFA $<5-10 \%$ En, PUFA n-6<4-8\% En, PUFA n-3<0.5-2.0\%; less than 3 portions of 50g each of vegetables a day [29]) En \%=percentage of energy of the daily diet; PUFA=Polyunsaturated fatty acids; PUFA n-6=Polyunsaturated fatty acids omega-6; PUFA n-3=Polyunsaturated fatty acids omega-3).

\section{Treatment}

The enrolled patients were allocated to the treatment with an active nutritional ingredient standardized in fatty acid $(\geq 90 \%)$ and phytosterols ( $\geq 5 \%$ ) from Serenoa repens, Borrago officinalis, Linum usitatissimum, Tritticum vulagare, Pynus sylvestris and Secale cereale (NaturSYN BeaulixirTM kindly provided by Amitalia S.r.l, Solaro, MI, Italy) (Table 1).

This product was formulated in gelatin soft-gels containing $300 \mathrm{mg}$ each.
All patients were requested to take two soft-gels of nutritional supplement every early morning for 6 months. The daily intake was monitored by a six-month calendar that was given to the volunteers at $\mathrm{T}_{0}$ and collected at the end of six months.

\section{Assessments}

Standardized global photographs of the front/temporal and vertex region were taken, by a digital camera, at the beginning of the study $\left(\mathrm{T}_{0}\right)$, three months later $\left(\mathrm{T}_{3}\right)$ and at the end of the study $\left(\mathrm{T}_{6}\right)$. The pictures of each subject were evaluated by an expert, who assessed the 
Citation: Zanzottera F, Nobile V, Bizzaro B, Michelotti A (2017) Efficacy of a Nutritional Supplement, Standardized in Fatty Acids and Phytosterols, on Hair Loss and Hair Health in both Women and Men. J Cosmo Trichol 3: 121. doi:10.4172/2471-9323.1000121

Page 4 of 7

hair density through a 7-point scale following a confirmed procedure [30]:

$$
\begin{aligned}
& +3 \rightarrow \text { greatly increased } \\
& +2 \rightarrow \text { moderately increased } \\
& +1 \rightarrow \text { slightly increased } \\
& \rightarrow \text { no change } \\
& -1 \rightarrow \text { slightly decreased } \\
& -2 \rightarrow \text { moderately decreased } \\
& -3 \rightarrow \text { greatly decreased }
\end{aligned}
$$

Trichoscopic images were also obtained by Dino-Lite digital microscope and four pictures at 50x magnification were reviewed for each case.

A self-assessment questionnaire focusing on hair loss, hair density, greasiness and hair shaft conditions (strength, softness, brightness and volume) was given to all subjects at $\mathrm{T}_{1}, \mathrm{~T}_{3}$ and $\mathrm{T}_{6}$.

Further questions on the overall satisfaction of the treatment and skin and nails health were asked to all patients.

\section{Results}

\section{In vitro}

Dosage of enzyme 5-alpha-reductase activity in culture of human keratinocytes (ATCC-PCS-200-010): The results are expressed as DHT released in the media during experimental period (mean value \pm dev.st.) and as mean percentage variation compared to the CTR (Figure 1).

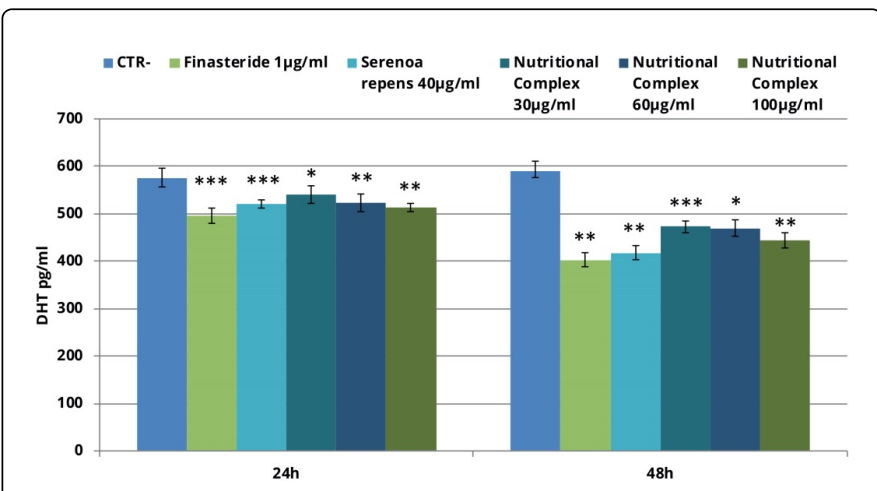

Figure 1: Dosage of DHT in cell culture at different experimental times (The results are expressed as mean value \pm dev. st. (expressed in $\mathrm{pg} / \mathrm{ml}) .{ }^{*}$ Indicates a statistically significant change compared to CTR-, $\mathrm{P}<0.05 ;{ }^{* *}$ Indicates a statistically significant change compared to CTR-, $\mathrm{P}<0.01$; ${ }^{* * *}$ Indicates a statistically significant change compared to CTR-, $\mathrm{P}<0.001)$.

After $24 \mathrm{~h}$ treatment, dosage of DHT in cell culture is reduced $13.9 \%$ by finasteride, $10.9 \%$ by nutritional complex at $100 \mu \mathrm{g} / \mathrm{ml}, 9.3 \%$ by the nutritional complex at $60 \mu \mathrm{g} / \mathrm{ml}, 6.1 \%$ by the nutritional complex at $30 \mu \mathrm{g} / \mathrm{ml}$ and $9.6 \%$ by Serenoa repens comparing to negative control.
Moreover, after $48 \mathrm{~h}$ treatment DHT is reduced $31.7 \%$ by finasteride, $24.7 \%$ by the nutritional complex at $100 \mu \mathrm{g} / \mathrm{ml}, 20.4 \%$ by the nutritional complex at $60 \mu \mathrm{g} / \mathrm{ml}, 11.3 \%$ by the nutritional complex at $30 \mu \mathrm{g} / \mathrm{ml}$ and $29.2 \%$ by the Serenoa repens, compared again with negative control.

The inhibitory activity of the nutritional complex towards the synthesis of dihydrotestosterone is time dependent, as longer is the incubation higher is the $5 a$ Red inhibition. Moreover, the results obtained with the three different dosages of the nutritional supplement suggest that higher is the dosage stronger is the $5 a$ Red inhibition, but further analysis needs to be done to confirm the data and to evaluate if a plateau level is going to be reached.

The product shows an inhibition of the total $5 a$ Red comparable to both finasteride and Serenoa repens, especially at $24 \mathrm{~h}$.

\section{Human trial}

Demography: A total of 30 patients were enrolled in the study. At baseline were defined age, hair condition, hair loss type, hairstyle, daily diet and potentials allergies for every patients, (Table 3).

\begin{tabular}{|l|l|l|l|l|}
\hline $\begin{array}{l}\text { Subjects, } \\
\mathbf{N}=\mathbf{3 0}\end{array}$ & $\begin{array}{l}\text { Age (years, } \\
\text { mean } \pm \text { SD) }\end{array}$ & $\begin{array}{l}\text { Androgenetic } \\
\text { alopecia/female } \\
\text { pattern hair } \\
\text { loss (N) }\end{array}$ & $\begin{array}{l}\text { Severe } \\
\text { telogen } \\
\text { effluvium (N) }\end{array}$ & $\begin{array}{l}\text { Stress and } \\
\text { food deficiency } \\
\text { hair loss (N) }\end{array}$ \\
\hline $\begin{array}{l}\text { Male, } \\
\mathbf{N}=15\end{array}$ & $35.9 \pm 10.8$ & 9 & 3 & 3 \\
\hline $\begin{array}{l}\text { Female, } \\
\mathbf{N}=15\end{array}$ & $36.9 \pm 10.9$ & 3 & 10 & 2 \\
\hline
\end{tabular}

Table 3: Demography of volunteers.

The female group was composed of: 2 post-breastfeeding women, 4 ladies in post-menopause and 9 girls of child breading age; 3 of them suffers of FPHL, 10 of telogen effluvium and 2 of stress or nutritional deficiencies hair loss. The male group was made up of: 6 men aged in between 20 and 30 years old, 5 in between 30 and 40 years old and 4 over 40; 9 of them suffers of AGA, 3 of severe telogen effluvium and 3 of stress or nutritional deficiencies hair loss.

All the 30 patients finished the study. The compliance was calculated form the daily calendar collected that the end of the study: $85 \%$ took all the requested capsules, $8 \%$ forgot the capsules for 1 to 2 days, $5 \%$ forgot them for 2 to 5 and $2 \%$ forgot to take the nutritional supplement for more than 5 days in the whole six months.

Trichoscopy: The analysis conducted through digital microscope show an improvement of hair density and new hair growth after 6 months treatment (Figure 2 above and below). Furthermore, an improvement of vascularization and reduction of greasiness at the follicle level have been evaluated (Figure 2 below and middle). These partial and macroscopic results need to be reconfirmed in a future study by software measurements of hair density and shaft.

In addiction has been noted that, women who experienced the reduction of greasiness, $93 \%$ of the volunteers, went through a reduced hair-washing tendency per week passing form four to three times a week, $56 \%$, and from three to two times a week, $44 \%$. This condition was not evaluated by the men as all the enrolled wash their hair daily. 
Citation: Zanzottera F, Nobile V, Bizzaro B, Michelotti A (2017) Efficacy of a Nutritional Supplement, Standardized in Fatty Acids and Phytosterols, on Hair Loss and Hair Health in both Women and Men. J Cosmo Trichol 3: 121. doi:10.4172/2471-9323.1000121

Page 5 of 7

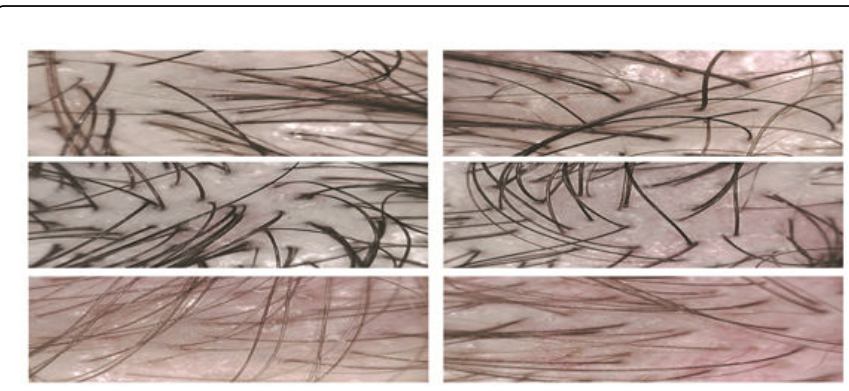

Figure 2: Trichoscopy of subjects 25 (above), 20 (middle) and 14 (below) at Time zero (left) and after 6 month of treatment (right).

Global photograph review: Photographs review and analysis show an interesting improvement of hair density already at $\mathrm{T}_{3}$; however, the major variances can be appreciated at $\mathrm{T}_{6}$. After 6 month treatment 83.3\% of subjects experience an increased hair density (Table 4). Reference photographs are shown in Figure 3.
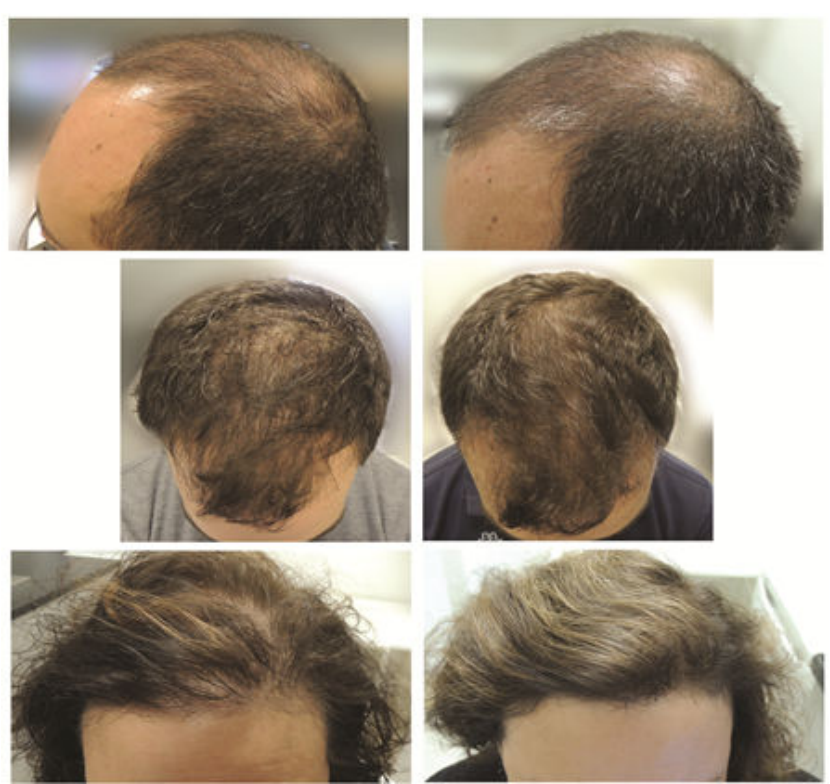

Figure 3: Global photographs of subjects 26 (above), 11(middle), 29 (below) at Time zero (left) and after 6 month of treatment (right).

\begin{tabular}{|c|c|c|c|c|}
\hline Hair Density & $\begin{array}{l}\text { Male } \quad \mathrm{N}=15 \\
(\%)\end{array}$ & $\begin{array}{l}\text { Female } \\
\mathrm{N}=15(\%)\end{array}$ & $\begin{array}{l}\text { Tot } \\
\text { (\%) }\end{array}$ & $\mathrm{N}=30$ \\
\hline -3: greatly decreased & 0 & 0 & & \\
\hline-2 moderately decreased & 0 & 0 & & \\
\hline-1 slightly decreased & 6.7 & 6.7 & 6.7 & \\
\hline 0 no change & 13.3 & 6.7 & 10.0 & \\
\hline 1 slightly increased & 20.0 & 26.7 & 23.3 & \\
\hline 2 moderately increased & 33.3 & 26.7 & 30.0 & \\
\hline
\end{tabular}

\begin{tabular}{|l|l|l|l|}
\hline 3 greatly increased & 26.7 & 33.3 & 30.0 \\
\hline
\end{tabular}

Table 4: Change in hair density T6/T0 evaluated by global photography, expressed in \% respect to the total component of the group.

Subject's assessment: Hair quality and hair loss reduction valued by the subjects show positive results confirming the photographic outcomes.

Some positive effects are already felt after one and three months of supplementation, but is at $\mathrm{T}_{6}$ that the volunteers experienced the best results.

After 6 month treatment $93.3 \%$ of the subjects see a general reduction in hair loss and $79.0 \%$ of them define it as significantly high; $83.3 \%$ notice a thicker and bulky hair; $90.0 \%$ feel the hair stronger with a better combing effect; finally, $88.5 \%$ experience a reduction of greasiness. Only few of them see an improvement in hair softness and brightness (Table 5).

\begin{tabular}{|l|l|l|l|}
\hline & $\mathbf{T}_{1}$ & $\mathbf{T}_{3}$ & $\mathbf{T}_{6}$ \\
\hline Overall hair loss is decreased & 80 & 83.3 & 93.3 \\
\hline Hair volume is improved & 76.7 & 73.3 & 83.3 \\
\hline Hair density is improved & 73.2 & 77.0 & 84.1 \\
\hline Hair softness is improved & 15.3 & 18.2 & 17.8 \\
\hline Hair strength is improved & 73.3 & 70.0 & 90.0 \\
\hline Hair brightness is improved & 10.1 & 10.5 & 11.6 \\
\hline Hair greasiness is reduced & 78.6 & 83.3 & 88.5 \\
\hline
\end{tabular}

Table 5: Self-assessment questionnaire (\% of subject in agreement (totally agree, agree and slightly agree) with the statement).

As secondary outcomes, $89.3 \%$ of subjects highlight an improvement of nails strength and $72.4 \%$ notice a reduction of skin greasiness and redness (data not shown).

At the end of the study, $93.0 \%$ of subjects are satisfied with the results. The product is well tolerated, with a good mouth feel and without any adverse event reported.

\section{Discussion}

As demonstrated in the last decade of studies and by the hospital practices, hair loss/ hair disorders have multifactorial etiology. It is commonly accepted that $5 \alpha$ Red activity is not the only pivotal point in hair pathology; indeed, follicular micro inflammation, oxidation and microcirculation at the hair bulb are the leading causes of these conditions [31-33]. Furthermore, the lack of immunity defense or nutritional deficiencies can increase the seriousness or enhance the disorders [34].

For these reasons, a nutritional supplement working on just one aspect of this complex pathology is not enough. A formulation carrying omega 3-6, antioxidant, phytosterols and vitamins can approach the multifactorial nature of this problem, instead.

Phytosterols, in particular $B$-sitosterol, have demonstrated their capacity to inhibit $5 a$ Red type I and II, which is responsible of 
the conversion of testosterone into dihydrotestosterone, worldwide recognized as one of the major players in hair miniaturization, leading to AGA or FPHL [35-37]. In this formulation, the phytosterols are mutually provided by saw palmetto, pine bark and rye grass extracts.

Not only phytosterols can inhibit the 5 aRed activity, but also omega-3 polyunsaturated fatty acid (PUFAs) and omega-6 (linolenic acid (LA) and $\gamma$-linolenic acid (GLA)), which can be found in very high concentration in linen seeds, borage oil, Serenoa repens and wheat germ oil [38].

Omega- 3 and omega- 6 have been studying for their potential activity on hair loss and hair condition for more than 20 years [39]. They are reported to exert an anti-oxidant activity and to reduce inflammation by directly influencing the arachidonic cascade. Furthermore, through the incorporation into the cell membrane they give a big help to the cell growth, regeneration and tissue fluidity [40].

Give that oxidation is now seen as one of the most important players in hair ageing process [41] and consequent discomfort, a big effort has been done to select ingredients highly standardized in phytosterols such as specifics pine bark and rye extract. Moreover, rye extract was demonstrated to stimulate the immune system by inducing the anti-inflammatory reactions and treating another cause of hair disorders.

The preliminary part of the study, conducted in vitro, demonstrate that this formulation can exert an inhibition of the total $5 a$ Red comparable to finasteride and Serenoa repens, especially at $48 \mathrm{~h}$. The inhibitory activity of the nutritional complex towards the synthesis of dihydrotestosterone is time dependent, as longer is the incubation higher is the 5 aRed inhibition. These results prove the inhibitory activity of a natural combination of phytosterols and omega 3-6 from Serenoa repens, linseed, borage, wheat oils, pine bark and rye grass on $5 a$ Red.

The nutritional complex, where Serenoa repens is present in less than $100 \mathrm{mg} /$ daily dose, eliminates regulatory issues in that countries where Serenoa repens is allowed only within $140 \mathrm{mg} / \mathrm{day}$, in the meanwhile provides an active complex composed of antiinflammatory, anti-oxidant and immunomodulator molecules at once.

The human study shows the positive effects of this natural complex supplementation on overall scalp coverage by an improvement of vascularization, hair diameter, strength and volume and a reduction of hair loss perception. These outcomes are clearly visible from the trichoscopy and global photographs review comparing $\mathrm{T}_{0}$ and $\mathrm{T}_{6}$.

Both the reduction of hair greasiness (revealed by the trichoscopy and self-assessment) and the improvement of hair quality (visible in the pictures and confirmed by the subject's assessment) demonstrate that this formulation is not only effective against $5 a$ Red but it also exerts its properties in a complete manner by restoring the physiologic condition of the healthy scalp. Significant there is also the improvement of nails strength and the reduction of skin redness and greasiness. These results confirm how the systemic activity specifically targets hair, skin and cutaneous annexes.

This is only a preliminary study, which provides interesting inputs on the effectiveness of the formulation complex standardized in fatty acids and phytosterols against hair loss and hair disorders: the positive response encourages to deepen the studies and to carry on a further randomized and placebo controlled study.

\section{References}

1. Sprenger K, Brown M, Stulberg DL (2003) Common hair loss disorder. Am Fam Physician 68: 93-102.

2. Buonocore D, Nobile V, Michelotti M, Marzatico F (2013) Clinical Efficacy of a cosmetic treatment by Crescina ${ }^{\circ}$ human follicle stem cell on healthy males with androgenetic alopecia. Dermalot Ther 3: 53-62.

3. Trueb RM (2002) Molecular mechanism of androgenetic alopecia. Exp Gerontol 37: 981-990.

4. Teede HJ, Misso ML, Deeks AA, Moran LJ, Stuckey BG, et al. (2011) Assessment and management of polycystic ovary syndrome: summary of an evidence-based guideline. Med J Aust 195: S65-112.

5. Scicchitano P, Dentamaro I, Carbonara R, Bulzis G, Dachille A, et al (2012) Cardiovascular risk in women with PCOS. Int J Endocrinol Metab 10: 611-618.

6. Caglar GS, Oztas E, Karadag D, Pabuccu R, Demirtas S (2011) Ischemiamodified albumin and cardiovascular risk markers in polycystic ovary syndrome with or without insulin resistance. Fertil Steril 95: 310-313.

7. Jones LN, Sinclair RD, Rivett DE (1997) Androgen metabolism and human hair growth. Chem Aust 64: 12-13.

8. Piraccini BM, Alessandrini A (2014) Androgenetic alopecia. Dermatol Venereol 149: 15-24.

9. Harcha wG, Martinez JB, Tsai T, Katsuoka K, Kawashima M, et al. (2014) A randomized, active and placebo-controlled study of the efficacy and safety of different doses of dutasteride versus placebo and finasteride in the treatment of male subjects with androgenetic alopecia. J Am Acad Dermatol 70: 489-498.

10. Aggarwal S, Thareja S, verma A, Bhardwaj TR, Kumar M (2010) An overview on $5 \alpha$-reductase inhibitiors. Steroids 75: 109-153.

11. Rinaldi S, Bussa M, Mascaro A (2016) Update on treatment of androgenetic alopecia. Eur Rev Med Pharmacol Sci 20: 54-58.

12. Mella JM, Perret MC, Manzotti M, Catalano HN, Guyatt G (2010) Efficacy and safety of finasteride therapy for androgenetic alopecia: a systematic review. Arch Dermatol 146: 1141-1150.

13. Braun-Falco O, Burgdorf WH, Plewig G, Wolff HH, L Andthaler M (2009) Braun-Falco's Dermatology. 3rd ed. Springer.

14. Roberts JL, Fiedler V, Imperato-McGinley J, Whiting D, Olsen E, et al. (1999) Clinical dose ranging studies with finasteride, a type 2 5alphareductase inhibitor, in men with male pattern hair loss. J Am Acad Dermatol 41: 555-563.

15. Kosman ME (1980) Evaluation of a new antihypertensive agent. Minoxidil. Jama 244: 73-75.

16. Devine BL, Fife R, Trust PM (1977) Minoxidil for severe hypertension after failure of other hypotensive drugs. British medical journal 2: 667-669.

17. Kreindler TG (1987) Topical minoxidil in early androgenetic alopecia. J Am Acad Dermatol 16: 718-724.

18. Lucky AW, Piacquadio DJ, Ditre CM, Dunlap F, Kantor I, et al. (2004) A randomized, placebo-control trial of $5 \%$ and $2 \%$ topical minoxidil solutions in the treatment of female pattern hair loss. J Am Acad Dermatol 50: 541-553.

19. Schweiger ES, Boychenko O, Bernstein RM (2010) Update on the pathogenesis, genetics and medical treatmentof patterned hair loss. J Drugs Dermatol 9: 1412-1419.

20. Friedman ES, Friedman PM, Cohen DE, Washenik K (2002) Allergic contact dermatitis to topical minoxidil solution: etiology and treatment. J Am Acad Dermatol 46: 309-312

21. Kirkil G, Hamdi Muz M, Seckin D, Sahin K, Kucuk O (2008) Antioxidant effect of zinc picolinate in patients with chronic obstructive pulmonary disease. Respir Med 102: 840-844.

22. Chimienti F, Aouffen M, Favier A, Seve M (2003) Zinc homeostasisregulating proteins: new drug targets for triggering cell fate. Curr Drug Targets 4: 323-338.

23. Oliveira KJ, Donangelo CM, de Oliveira AV, da Silveira Jr CL, Koury JC (2009) Effect of zinc supplementation on the antioxidant, copper, and 
Citation: Zanzottera F, Nobile V, Bizzaro B, Michelotti A (2017) Efficacy of a Nutritional Supplement, Standardized in Fatty Acids and Phytosterols, on Hair Loss and Hair Health in both Women and Men. J Cosmo Trichol 3: 121. doi:10.4172/2471-9323.1000121

Page 7 of 7

iron status of physically active adolescents. Cell Biochem Funct 27 162-166.

24. Hirsburgh JM, Kelsey PA, Therrien CA, Gavino AC, Reichenberg JS (2016) Adverse Effects and Safety of 5-alpha Reductase Inhibitors (Finasteride, Dutasteride): A Systematic Review. Clin Aest Dermatol 9: 56-62.

25. Rushton DH (2002) Nutritional factors and hair loss. Clin Exp Dermatol 27: 396-404.

26. Haneke E, Baran R (2011) Micronutrients for hairs and nails. In Krutmann J, Humbert P, eds. Nutrition for Helathy skin-Strategies for clinical and cosmetics practices. Berlin Heidelberg: Springer 149-163.

27. Stough D, Stenn K, Haber R, Parsley WM, Vogel JE, et al. (2005) Psychological effect, pathophysiology, and management of androgenetic alopecia in men. Mayo Clin Proc 80: 1316-1322.

28. Rossp A, Marp E, Scarn M, Garelli V (2012) Comparative effectiveness of finasteride vs serenoa repens in male androgenetic alopecia: a two-year study. Int J Immunopathol Pharmacol 25: 1167-1173.

29. Sinu (2014) LARN IV REVISIONE: Livelli di Assunzione di Riferimento di Nutrienti ed energia, SICS Editore.

30. Kaufman K, Binkowitz B, Savin R, Canfield D (1995) Reproducibility of global photographic assesments of patients with male pattern baldness in a clinical trial with finasteride. J Invest Dermatol 104: 659.

31. Whiting DA (1996) Chronic telogen effluvium: increased scalp hair shedding in middle-aged women. J Am Acad Dermatol 35: 899-906.
32. Jaworsky C, Kligman AM, Murphy GF (1992) Characterization of inflammatory infiltrates in male pattern alopecia: implications for pathogenesis. Br J Dermatol 127: 239-246.

33. Trüeb RM (2009) Oxidative Stress in Ageing of Hair. Int J Trichology 1: 6-14.

34. Qi J, Garza LA (2014) An Overview of Alopecias, Cold Spring Harb Perspect Med 4: a013615.

35. Murugusundram S (2009) Serenoa Repens. Does It have Any Role in the Management of Androgenetic Alopecia. J Cutan Aesthet Surg 2: 31-32.

36. Alsantali A, Shapiro J (2009) Androgens and hair loss. Curr Opin Endocrinol Diabetes Obes 16: 246-256.

37. Piraccini BM, Alessandrini A (2014) Androgenetic alopecia. J Ital Dermatol Venerol 149: 15-24.

38. Liang T, Liao S (1992) Inhibition of steroids $5 a$-reductase by specific aliphatic unsaturated fatty acids. Biochem J 285: 557.

39. Le Floc'h C, Cheniti A, Connétable S, Piccardi N, Vincenzi C, et al. (2014) Effect of nutritional supplement on hair loss in women. J of Cosm Derm 14: 76-82.

40. Humbert P, Binda D, Robin S (2011) Beauty from inside:nutrition-based strategies in cosmetic dermatology. Nutrition for healthy skin 189-196.

41. Trueb RM (2009) Oxidative stress in ageing of hair. Int J Trichology 1: 6-14. 